\title{
Nystatin-loaded Polyelectrolyte Complex Films as a Mucoadhesive Drug Delivery System for Potential Buccal Application
}

\author{
Efraín Armenta-Rojas 1(D), José Manuel Cornejo-Bravo 1,*iD, Aracely Serrano-Medina ${ }^{2}$ (D), Eduardo \\ Alberto López-Maldonado ${ }^{1(D)}$, Amelia Olivas-Sarabia ${ }^{3}$ (D) , Nydia Alejandra Castillo-Martínez ${ }^{4(D)}$, Luis \\ Jesús Villarreal-Gómez ${ }^{1,5}$ iD , Lilia Angélica Hurtado-Ayala 1 (D)
}

1 Faculty of Chemical Sciences and Engineering, Autonomous University of Baja California, Otay Unit, Tijuana, Baja California, Mexico; efrain.armenta@uabc.edu.mx (E.A.-R.), jmcornejo@uabc.edu.mx (J.M.C.-B.), elopez92@uabc.edu.mx (E.A.L.-M.), lilyhurtado@uabc.edu.mx (L.A.H.-A.);

2 Faculty of Medicine and Psychology, Autonomous University of Baja California, Otay Unit, Tijuana, Baja California, Mexico; serrano.aracely@uabc.edu.mx (A.S.-M.);

3 Center of Nanoscience and Nanotechnology, National Autonomous University of México, Ensenada, Baja California, Mexico; ameliaolivas610@gmail.com (A.O.-S.);

4 Faculty of Health Sciences, Autonomous University of Baja California, Valle de las Palmas Unit, Tijuana, Baja California, Mexico; nydia.castillo@uabc.edu.mx (N.A.C.-M.);

5 Faculty of Engineering and Technology Sciences, Autonomous University of Baja California, Valle de las Palmas Unit, Tijuana, Baja California, Mexico; luis.villarreal@uabc.edu.mx (L.J.V.-G.);

* Correspondence: jmcornejo@uabc.edu.mx (J.M.C.-B.);

Scopus Author ID 6603644341

Received: 16.06.2021; Revised: 25.07.2021; Accepted: 28.07.2021; Published: 15.08.2021

\begin{abstract}
According to the World Health Organization, one of the most prevalent fungal diseases globally is oropharyngeal candidiasis. The formulations of nystatin used for its treatment have several disadvantages, including a low residence time at the infection site. This study aimed to prepare and characterize polyelectrolyte films of chitosan-gum-arabic and chitosan-polygalacturonic acid using the "Solvent-Casting" technique, loaded with nystatin, to achieve a mucoadhesive and sustained release system intended for the oral cavity. The obtained films were characterized to determine the interaction between the polymers, their morphological characteristics, mucoadhesive capacity, and drug release kinetics. Scanning electron microscopy was used to determine the films' morphology, while infrared spectroscopy, differential scanning calorimetry, and thermogravimetric analysis demonstrated the interaction between the polymers. Additionally, the films' antifungal activity was tested against three strains of two Candida species. The films of both formulations showed mucoadhesive capacity and a nystatin release profile explained by the Korsmeyer-Peppas model. Also, significant antifungal activity was found. These findings indicate that polyelectrolyte complex-based films are a plausible nystatin release system for oral application.
\end{abstract}

Keywords: polyelectrolyte films; mucoadhesive; chitosan; nystatin; candidiasis.

(C) 2021 by the authors. This article is an open-access article distributed under the terms and conditions of the Creative Commons Attribution (CC BY) license (https://creativecommons.org/licenses/by/4.0/).

\section{Introduction}

Oropharyngeal candidiasis (OPC) is one of the most prevalent fungal infections in the world [1]. OPC occurs when the yeast adheres and penetrates the oral tissue [2]. Even though many Candida species such as $C$. dubliniensis, C. glabrata, Pichia kudriavzevii (C. krusei), $C$. kefyr, C. parapsilosis, C. stellatoidea, and C. tropicalis have been isolated from patients with 
OPC [3], more than $80 \%$ of the diagnosed cases are caused by Candida albicans due to its greater adherence capacity and level of pathogenicity [4].

Several factors can lead to the development of OPC, such as the use of dentures, corticosteroid inhalers, leukemia; malnutrition; endocrine dysfunction such as diabetes; systemic chemotherapy; radiation therapy; and the use of systemic corticosteroids, immunomodulatory drugs, xerogenic drugs, broad-spectrum antimicrobials, and immunosuppressed states caused by the human immunodeficiency virus (HIV) [5-7].

HIV patients are of particular interest since the immunosuppression caused by the reduced $\mathrm{CD}^{4+} \mathrm{T}$ lymphocyte count, viral charge, and local factors such as xerostomia are risk factors for developing this type of infection. $50 \%$ of these patients are carriers of some Candida species [8,9], and over 80-90\% of them develop OPC at some stage of the disease $[10,11]$.

Recent studies have identified the prevalence and factors associated with oral Candida colonization and candidiasis in institutionalized HIV-positive children and teenagers. A high prevalence of colonization was found with different strains of Candida isolated from over 50\% of the patients. The factors associated with the colonization were: male gender, a high viral load, a low $\mathrm{CD}^{4+}$ cells count, and less than three years into High Active Antiretroviral Treatment. The isolated strains also showed a significant antimicrobial resistance [12].

Nystatin (NYS) is the drug of choice for the treatment of OPC [13]. It is an antibiotic obtained from Streptomyces noursei, which has a fungicide effect against Candida spp.; the use of NYS has proven to decrease or prevent the yeast's adherence to the epithelial cells avoiding their colonization and, therefore, the risk of infection [14,15]. However, this drug is not absorbed in the gastrointestinal tract, and its systemic administration is considerably toxic [16]. Therefore, the clinical use of NYS is restricted to superficial infections. Most patients with OPC are treated with NYS as an oral suspension, lozenges, or oral tablets. These formulations require several doses a day [17] due to their short residence time in the oral mucosa. The low bioavailability is reduced even further by saliva dilution; other disadvantages include an unpleasant taste, viscous consistency, and low water solubility of the drug $[18,19]$.

Therefore, there is a need for formulations retained in the infection site and release antimicrobials in a sustained manner to avoid under therapeutic levels that may lead to antimicrobial resistance. To address this issue, one approach is developing bioadhesive formulations based on natural polymers [20].

Natural polymers are mostly derived from renewable resources and include polysaccharides, proteins, lipids, polyphenols, among others [21]. Natural polymers are widely used in drug release systems due to their availability, compatibility, degradation under natural and physiological conditions, and bioadhesive properties [22].

The phenomenon of mucoadhesion has been widely studied in recent decades. This property has been incorporated in various pharmaceutical forms to increase the residence time at the absorption site, improving its effectiveness. One of the strategies is the use of polyelectrolyte complexes (PEC) as a platform for drug loading and release [23].

PEC are networked with a non-permanent structure resulting from the mixture of solutions of polymers (polyelectrolytes) with opposite charges, resulting in spontaneous association by forming electrostatic bonds, strong but reversible. The formation and stability of polyelectrolyte complexes depend on several factors: the degree of ionization of each polyelectrolyte, the charge density, the concentration of the polyelectrolytes, and the nature of distinct ionic groups [24]. 
Chitosan (CHI) is the main polycation used to produce these complexes. CHI can be obtained with different degrees of deacetylation and molecular weights from chitin. CHI possesses cationic amino groups that can interact electrostatically with anionic polyelectrolytes to form polyelectrolyte complexes. Examples of polyanions that may interact with chitosan include polygalacturonic acid (PGA), gum arabic (GA), sodium alginate, carrageenan, and carboxymethyl cellulose. Recently, these have been used to design specific drug release systems depending on the required properties [25-27].

This study is aimed to develop and evaluate chitosan-based mucoadhesive polyelectrolyte systems for the sustained release of NYS, as a possible drug delivery system for the treatment of buccopharyngeal candidiasis.

\section{Materials and Methods}

\subsection{Materials.}

Chitosan low molecular weight (50,000-190,000 Da) 75-85\% deacetylated (SigmaAldrich), gum arabic (Spectrum), polygalacturonic acid (Sigma-Aldrich), nystatin $+85 \%$ (Acros Organics BVBA), potassium phosphate monobasic (Fermont), potassium phosphate dibasic (Mallinckrodt), nutrient agar (BBL); Candida albicans ATCC 14053, ATCC 90028 and a clinical strain of Pichia kudriavzevii (C. krusei) WT were supplied by the Microbiology Department of the Universidad Autonoma de Baja California, Facultad de Ciencias de la Salud. HPMC (MethocelTM 4000 DuPont) tablets were obtained by direct compression in a Carver press (200 mg polymer, $1.3 \mathrm{~cm}$ die, $4000 \mathrm{lb} / \mathrm{in}^{2}$ compression pressure). All other chemicals were of analytical or pharmaceutical grade.

\subsection{Preparation of PEC films.}

PEC films were prepared using the solvent casting technique [28]. A CHI solution was prepared by slowly adding $750 \mathrm{mg}$ of the polymer to $15 \mathrm{~mL}$ of $0.1 \%$ acetic acid in constant stirring until fully dissolved. An equal amount of the polyanion (gum arabic [GA] or polygalacturonic acid [PGA]) was also dissolved in $15 \mathrm{~mL}$ of distilled water. The PEC was obtained by gradually adding the polyanion solution to $\mathrm{CHI}$ solution with continuous stirring using a homogenizer at $5000 \mathrm{rpm}$ for $10 \mathrm{~min}$, finally adding the drug solution ( $25 \mathrm{mg}$ of NYS in $20 \mathrm{~mL}$ ethanol). The mixture was cast in horizontally leveled silanized glass plates $(10 \mathrm{x} 10$ $\mathrm{cm}$ ), drying in an oven at $40^{\circ} \mathrm{C}$ for $48 \mathrm{~h}$. The dried films were carefully removed from the plates and visually inspected for any imperfections or air bubbles. Films were stored at room temperature.

\subsection{Morphological characteristics of PEC films using scanning electron microscopy.}

The surface characteristics of both placebo and NYS-loaded PEC films were studied using a scanning electron microscope (SEM) (JIB-4500, Jeol, Japan). The samples were mounted on metal stubs with the double-sided adhesive band and then sputtered with a layer of gold for the 50s under $15 \mathrm{~mA}$ current to give it electrically conductive properties. The crosssectional images of film samples were also obtained [29]. 


\subsection{FT-IR spectroscopy.}

FT-IR spectroscopy (FT-IR Nicolet ${ }^{\mathrm{TM}}$ iS $\mathrm{S}^{\mathrm{TM}} 5,650-4000 \mathrm{~cm}^{-1}, 16$ scans) was performed of CHI, GA, PGA, the placebo, and NYS-loaded films.

\subsection{Differential scanning calorimetry and thermogravimetric analysis.}

Differential scanning calorimetry (DSC) and thermogravimetric analysis (TGA) studies were performed (SDT Q600, TA Instruments, USA) to confirm complex formation. Studies were performed for placebo PEC films and PEC films containing NYS. Samples (1.5-3 mg) were placed in aluminum cells and heated at $10^{\circ} \mathrm{C} / \mathrm{min}$ over a temperature range of $20-400^{\circ} \mathrm{C}$ in a nitrogen atmosphere.

\subsection{Swelling studies.}

The swelling behavior of the PEC films was evaluated by the weighing method. Squares of $2 \times 2 \mathrm{~cm}$ were cut from the film. 12 squares were individually weighed and allowed to swell on a pH $6.75 \mathrm{PBS}$ solution at $37^{\circ} \mathrm{C}$. The film's weight was determined at different time intervals $(0.25,0.5,1,2,3,5$, and $6 \mathrm{~h})$. The water uptake was calculated using the following equation:

$$
S_{w}=\frac{W_{t}-W_{0}}{W_{0}}
$$

where $S_{\mathrm{w}}$ is the film's water uptake capacity, $\mathrm{W}_{\mathrm{t}}$ is the weight of the swollen samples after time $\mathrm{t}$, and $\mathrm{W}_{0}$ is the original weight. Measurements were carried out in triplicate.

\subsection{Drug content.}

Film portions of $2 \times 2 \mathrm{~cm}$ were cut from different areas of the films. The films were dissolved in $100 \mathrm{~mL}$ of $\mathrm{pH} 6.75$ phosphate buffer. The obtained samples were assayed for NYS content spectrophotometrically at the pre-scanned wavelength $(406 \mathrm{~nm})$. The drug concentration was calculated by calculating the drug concentration reference to the appropriate calibration curve constructed in the same buffer.

\subsection{In vitro release studies of NYS from PEC films.}

The films were cut into $2 \times 2 \mathrm{~cm}$ squares and weighted; each square was placed in a $500 \mathrm{~mL}$ beaker containing $400 \mathrm{~mL}$ of $\mathrm{pH} 6.75 \mathrm{PBS}$ buffer, previously warmed at $37^{\circ} \mathrm{C}$, shaken at $50 \mathrm{rpm}$. At different time intervals (5 min, $10 \mathrm{~min}, 15 \mathrm{~min}, 0.5,1,2,3,4,5,6,7,8,9,10$, $11,12,20$, and $24 \mathrm{~h}$ ), a $5 \mathrm{~mL}$ sample of the release medium was taken and replaced with an equal volume of fresh buffer solution. The samples were assayed for NYS content spectrophotometrically as previously described.

\subsection{In vitro determination of antifungal activity.}

The films were tested for their antifungal activity against Candida albicans and Pichia kudriavzevii (C. krusei) using inoculated Müller-Hinton agar plates with $2 \%$ glucose and $0.5 \mathrm{mg} / \mathrm{mL}$ of methylene blue [30]. Three films cut as circles of $7 \mathrm{~mm}$ diameter for each formulation were transferred onto the surface of the inoculated agar plate and incubated at 37 ${ }^{\circ} \mathrm{C}$. The diameter of the inhibition zone was measured after $72 \mathrm{~h}$. The mean inhibition zones and standard deviation were calculated. The antimicrobial activity for placebo PEC films was also tested. 


\subsection{Adhesion properties of films.}

Determination of adhesive properties was performed by texture analysis (CT3, Brookfield, Canada). Each film's adhesiveness was obtained by measuring the force required to detach each formulation from a disk of freshly excised rabbit intestinal mucosa [31]. A portion of each film $(1 \times 1 \mathrm{~cm})$ was bound to the upper end of the cylindrical probe, and mucosa discs were horizontally attached to the lower end of the testing apparatus. Prior to testing, the mucosa was hydrated in pH 6.75 PBS for $5 \mathrm{~min}$. The films were allowed to attach to the mucosa for $30 \mathrm{~s}$, and then the probe was moved upwards at $1.0 \mathrm{~mm} / \mathrm{s}$.

As a mucoadhesive reference, hydroxypropyl methylcellulose tablets were tested using the same parameters. Whatman filter paper was used as a negative control [32]. The force required to detach the film from the mucosa surface was found via the analysis as the maximum force $(\mathrm{F} ; \mathrm{N})$. The work of adhesion $(\mathrm{Wad} ; \mathrm{mJ})$ was calculated from the area under the curve [33].

\subsection{Statistical analysis.}

All results are represented as mean \pm standard error (SE) for each data group. Statistics were analyzed using Graphpad Prism 8. Student's t and ANOVA tests with multiple Tukey test comparisons were performed to assess the differences between formulations, considering a $\mathrm{p}$ $<0.05$ as significant.

\section{Results and Discussion}

\subsection{Characterization of polyelectrolyte complex film.}

\subsubsection{Physical characteristics of PEC films: appearance, texture, and thickness}

The chitosan/polygalacturonic acid placebo films cast were yellow and showed a rough surface. Its texture was rigid and brittle (Figure 1a); the films of the same formulation loaded with NYS had a rougher surface and a more intense color (Figure 1b). The chitosan/gum arabic placebo films cast by the same technique were clearer, showed a smooth surface, and their texture was more flexible and less brittle than the other formulation (Figure 1c). A more opaque and intense coloration was observed for the NYS-loaded film (Figure 1d). Several authors have found similar results in the color and texture of PECs films [34-36].

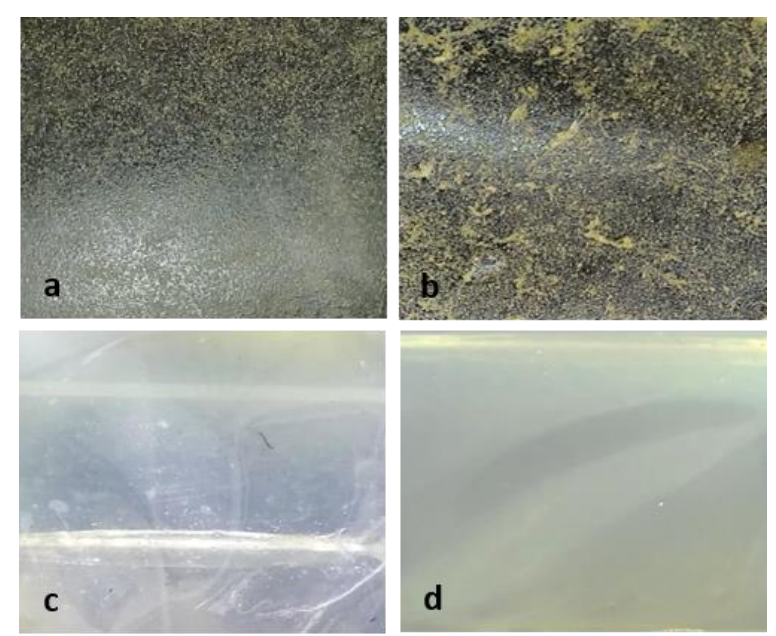

Figure 1. Macroscopic Morphology of Chitosan PEC films, x1 magnification of (a) CHI-PGA placebo film; (b) CHI-PGA film loaded with NYS; (c) CHI-GA placebo film; (d) CHI-GA loaded with NYS. 
The flexibility and homogenous appearance of the films are attributed to residual, unreacted, polymeric functional groups [37]. These characteristics are desirable for the buccal application since the formulation must be able to adapt to the shape of different buccal structures without cracking or breaking.

The thickness of the films was: CHI-GA: $0.065 \pm 0.005 \mathrm{~mm}$, CHI-GA-NYS: $0.067 \pm$ $0.009 \mathrm{~mm}$, CHI-PGA: $0.065 \pm 0.023 \mathrm{~mm}$, CHI-PGA-NYS: $0.062 \pm 0.009 \mathrm{~mm}$. No statistically significant difference was found between the formulations with or without NYS.

\subsubsection{Morphological characteristics of PEC films by SEM}

The morphology of all PEC films was assessed using SEM. Surface micrographs are shown in Figure 2. The placebo CHI-GA film surface (Figure 2a) was predominantly smooth and compact with no apparent pores, and the cross-section was dense (Figure 2e). The surface and cross-section morphologies of the film showed no apparent change with the incorporation of the drug aside from a few drug crystals (Figures $2 b$ and 2f). The placebo CHI-PGA films showed a rough and irregular surface (Figures $2 \mathrm{c}$ and $2 \mathrm{~g}$ ). Drug crystals were observed on the surface of the film containing NYS (Figure 2d). The surface of the film CHI-PGA-NYS is also rough. Further studies are required to explain the differences in the surface characteristics of the different films prepared.

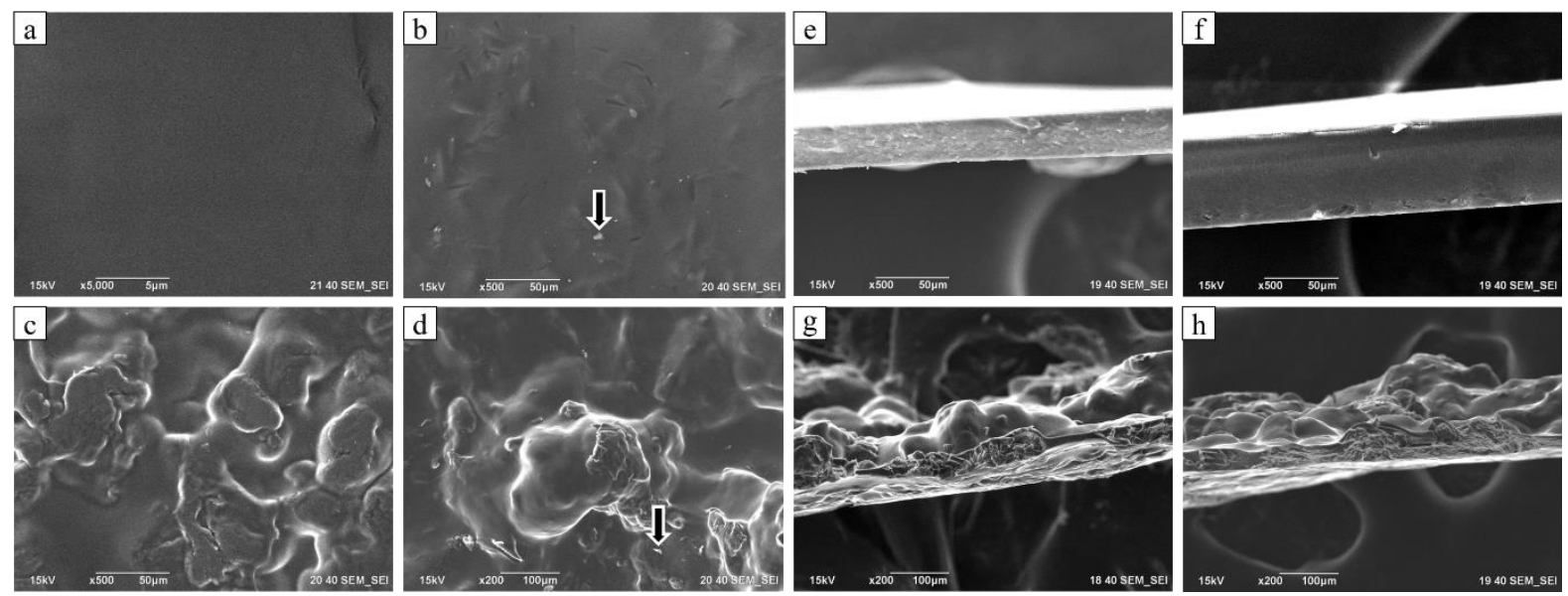

Figure 2. Scanning electron micrographs for: (a) CHI-GA; (b) CHI-GA-NYS; (c) CHI-PGA; (d) CHI-PGANYS; (e) CHI-GA cross-section; (f) CHI-GA-NYS cross-section; (g) CHI-PGA cross-section; (h) CHI-GANYS cross-section. Arrows indicate precipitated drug crystals.

\subsubsection{FT-IR spectroscopy.}

Acquired FT-IR spectra of CHI, GA, and their PECs showed absorption bands around $3300 \mathrm{~cm}^{-1}$, typical for $-\mathrm{O}-\mathrm{H}$ stretching vibrations, and around $2900 \mathrm{~cm}^{-1}$, which correspond to $-\mathrm{C}-\mathrm{H}$ stretching vibrations. The main bands of NYS were observed with the presence of skeletal vibrations. The band found at $1701.1 \mathrm{~cm}^{-1}$ is related to stretching vibrations of $\mathrm{C}=\mathrm{O}$ bond of an ester group, the wideband at $3353 \mathrm{~cm}^{-1}$ corresponds to the overlapping of - $\mathrm{OH}$ and -NH groups signals [38]. CHI peaks located around $1645.44 \mathrm{~cm}^{-1}, 1579.99 \mathrm{~cm}^{-1}$ were related to amide I and amide II bands from N-H group, respectively [39]. The peaks at $1602 \mathrm{~cm}^{-1}$ and $1419 \mathrm{~cm}^{-1}$ were related to $-\mathrm{C}$ - and $-\mathrm{COOH}$ stretching vibration for GA, and the peak at 1730 $\mathrm{cm}^{-1}$ corresponding to the vibration of non-ionized carboxylic groups $\mathrm{C}=\mathrm{O}$ of the polygalacturonic acid (Figure 3).

The spectra of the PEC showed the absence of the absorption bands at $1730 \mathrm{~cm}^{-1}$ from PGA and $1579.99 \mathrm{~cm}^{-1}$ from $\mathrm{CHI}$, as well as a significant reduction of signals characteristic 
for amines in the structure of CHI: $1645.44 \mathrm{~cm}^{-1}$ and $1322.84 \mathrm{~cm}^{-1}$. Asymmetric and symmetric $\mathrm{N}-\mathrm{H}$ deformation vibrations can explain shifts in wavelength and broadness in the bands in protonated amines, asymmetric stretching vibrations in the amide I and amide II bands, and carboxylate ions after complexation [40]. Peak changes corresponding to - $\mathrm{COOH}$ groups indicate a complexation according to the literature [41].

The absence of new absorption bands in PECs confirms that no chemical reactions occurred between the polymers. Lower peak intensities indicate that a high percentage of characteristic functional groups from $\mathrm{CHI}$ and the polyanions interacted with each other (functional groups were not free to absorb the IR signal), as previously reported by ArgüellesMonal et al. [42] and Tsai et al. [43].
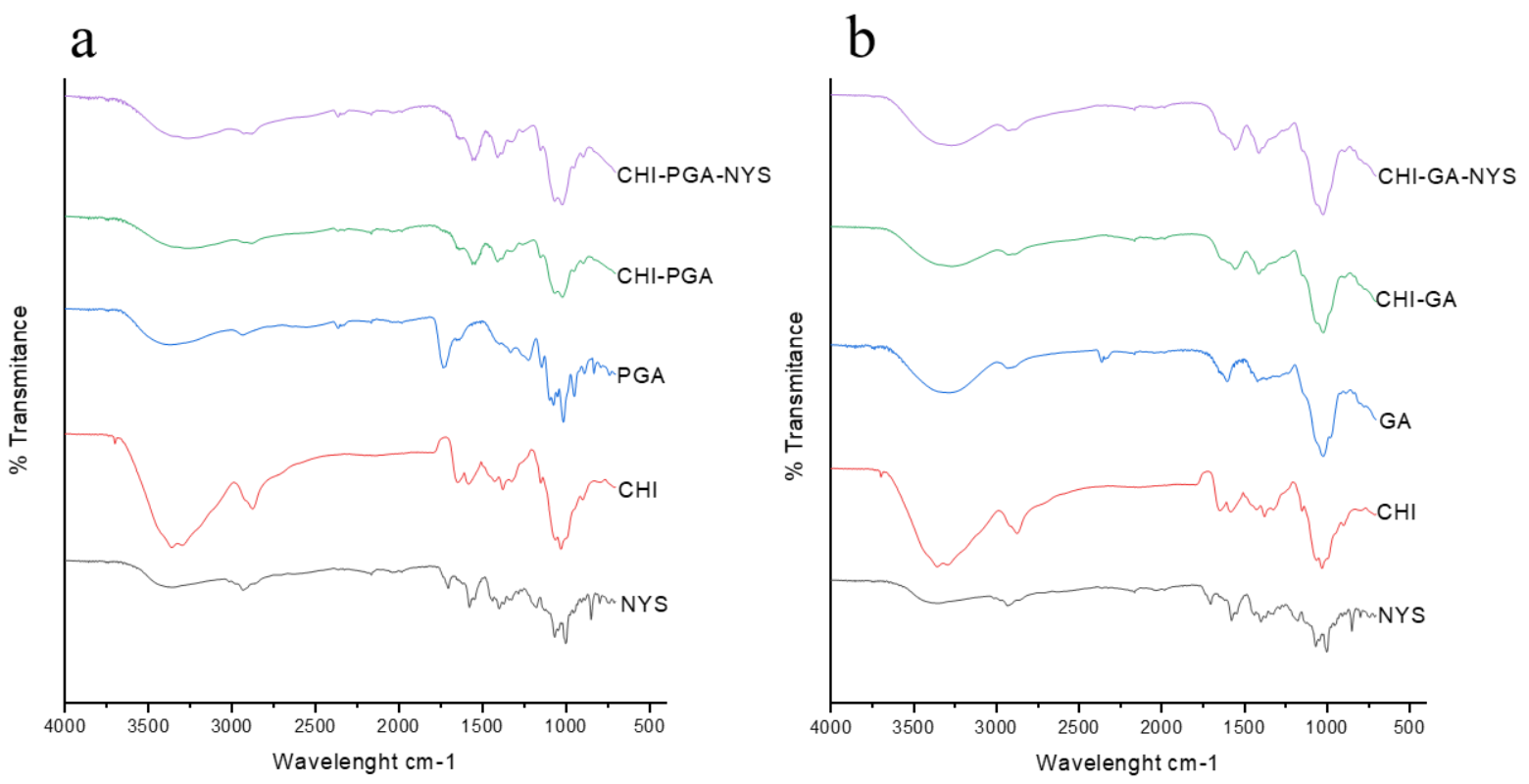

Figure 3. FT-IR spectra of (a) CHI, PGA, NYS, CHI-PGA, and CHI-PGA-NYS; (b) CHI, GA, NYS, CHI-GA, and CHI-GA-NYS.
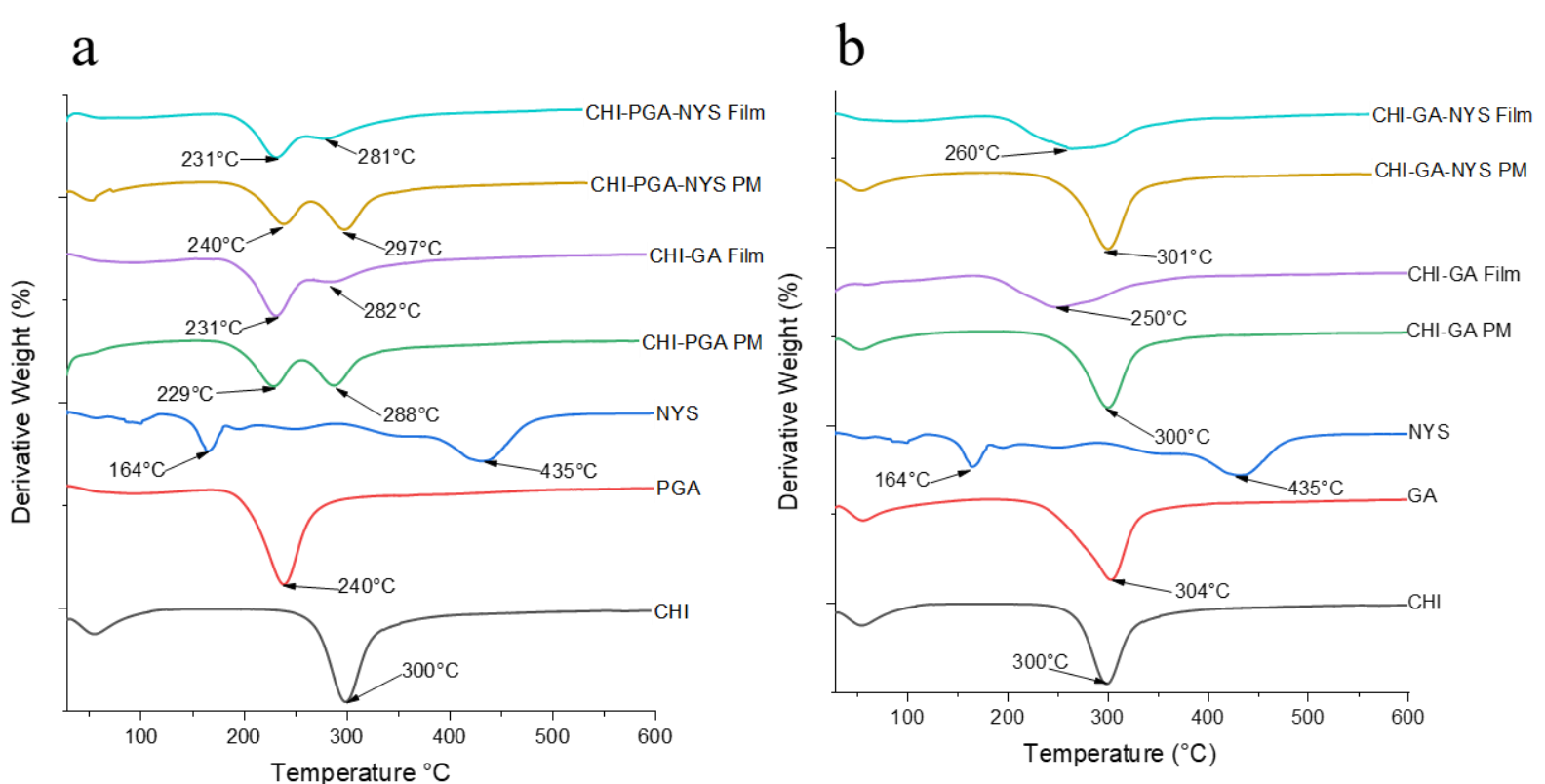

Figure 4. TGA thermograms of (a) CHI, PGA, NYS, their physical mixture (PM), and films; (b) CHI, GA, NYS, their PM, and films. 
3.1.4. Thermogravimetric analysis (TGA) and differential scanning calorimetry (DSC).

Figures 4 and 5 show the thermograms of CHI, PGA, GA, NYS, their physical mixture, and the polyelectrolyte films. All materials showed an initial endothermic process and weight loss due to moisture evaporation from the samples. $\mathrm{CHI}$ and $\mathrm{GA}$ had thermal events close to $300^{\circ} \mathrm{C}$ while PGA degraded at $240^{\circ} \mathrm{C}$ and NYS showed two peaks at $164^{\circ} \mathrm{C}$ and $435^{\circ} \mathrm{C}$. In the physical mixture of CHI and PGA, the peaks of both polymers can be seen. This result was not observed in the CHI-GA mixture since both polymers showed a very similar thermal behavior. The PEC films showed the same peaks as the physical mixtures; however, they appeared smaller and lower temperatures. The shift to a lower temperature in the complex's thermal degradation indicates a loss of organization due to the interaction between chitosan and the polyanions, being this the main evidence of the formation of a complex between the polymers [44]. The lack of an NYS degradation peak, both in the physical mixture and films, may be attributed to the low concentration of the drug in the formulations.
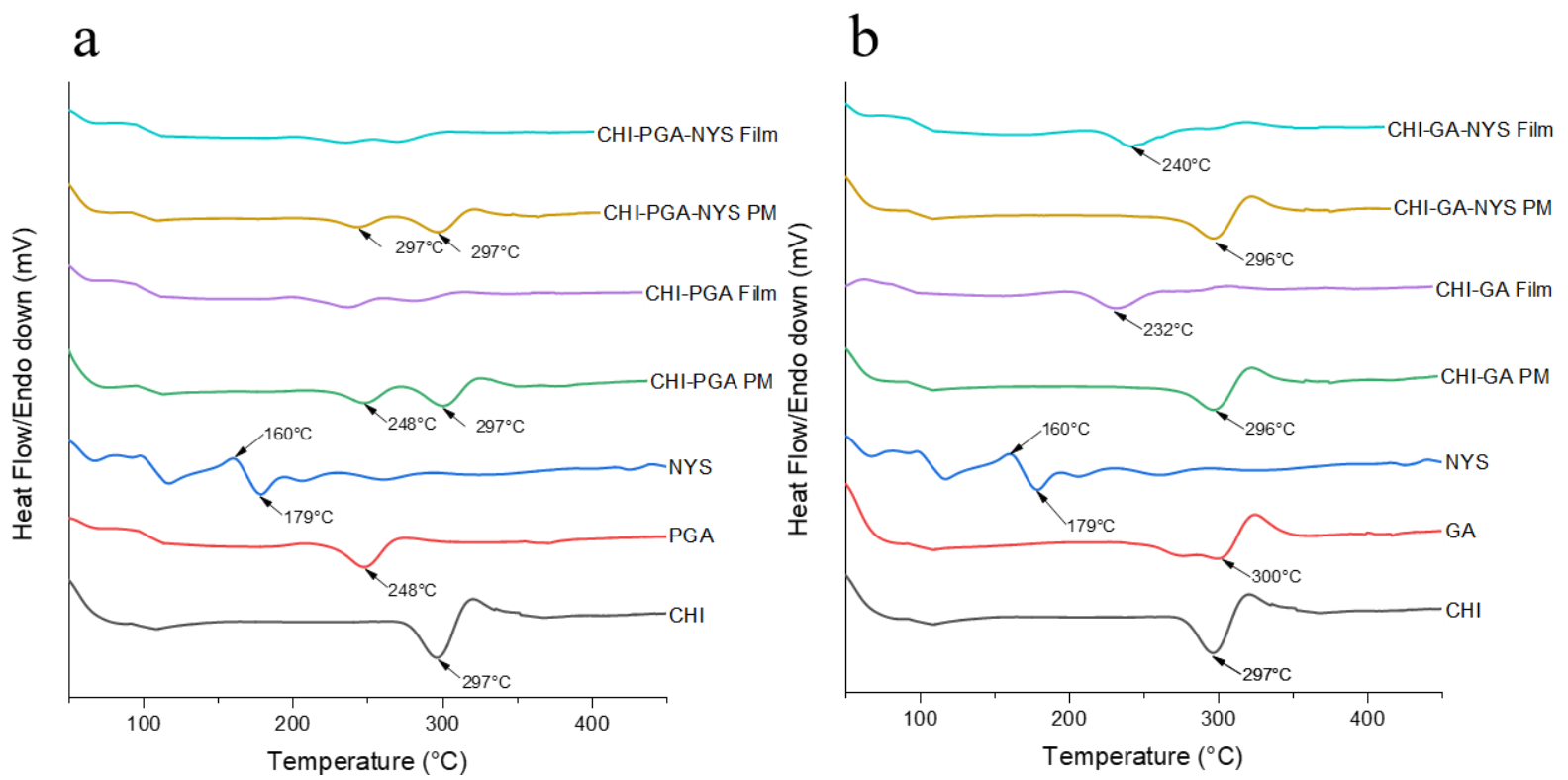

Figure 5. DSC Thermograms of (a) CHI, PGA, NYS, their physical mixture (PM), and films; (b) CHI, GA, NYS, their PM, and films.

\subsubsection{Drug content and swelling degree of PEC films.}

No statistically significant difference was found between the content of NYS or the swelling degree of the film formulations (Table 1); both films showed a significant water uptake and kept their integrity over the experiment period.

Table 1. Experimental results for drug content and swelling degree $(3 \mathrm{~h})$ of polyelectrolyte complex films (mean

\begin{tabular}{|c|c|c|c|c|c|}
\hline Formulation & $\begin{array}{c}\text { CHI-PGA } \\
\text { placebo }\end{array}$ & $\begin{array}{l}\text { CHI-GA } \\
\text { placebo }\end{array}$ & CHI-PGA-NYS & CHI-GA-NYS & p-value \\
\hline $\begin{array}{l}\text { Drug content } \\
\left(\mathrm{mg} / \mathrm{cm}^{2}\right)\end{array}$ & - & - & $0.1476 \pm 0.029$ & $0.1485 \pm 0.017$ & $\begin{array}{c}t=0.04637 \\
d f=4 \\
p=0.964\end{array}$ \\
\hline Swelling degree & $3.5 \pm 0.21$ & $3.64 \pm 0.17$ & $3.78 \pm 0.08$ & $3.88 \pm 0.20$ & $\begin{array}{c}F=2.607, \\
p=0.124\end{array}$ \\
\hline
\end{tabular}

The films' water uptake was high during the first $3 \mathrm{~h}$, followed by a plateau for swelling. However, passing the $6 \mathrm{~h}$ mark, the CHI-GA-NYS film appeared to be dissolving rather than 
absorbing water, unlike the CHI-PGA-NYS film that didn't lose its integrity at any point. The results can be explained by the difference in the matrix network structure's resistance to water molecules' movement [45]. It has been reported that the interaction between the polycation and the polyanion would cause a tightening of the network resulting in reduced swelling capacity [46].

\subsection{In vitro release studies of NYS from films.}

An initial fast release of NYS from both formulations was observed (Figure 6), probably due to the drug present on the films' surface since the scanning electron micrographs confirmed that the drug is dispersed in the PEC films surface. Both films showed a burst effect followed by a moderate release profile, which may benefit buccal application as a higher release rate at the initial dosing time could achieve an immediate therapeutic level of the drug followed by a slower release rate to maintain the concentration above the minimal inhibitory. Both formulations showed a very similar release profile, releasing $55 \%$ of the drug by the second hour and $84 \%$ in $24 \mathrm{~h}$. Kassem et al. observed similar behavior on tetracycline release from PEC for periodontal application. The authors attribute the results to the rapid dissolution of the water-soluble antibiotic from the film surface.

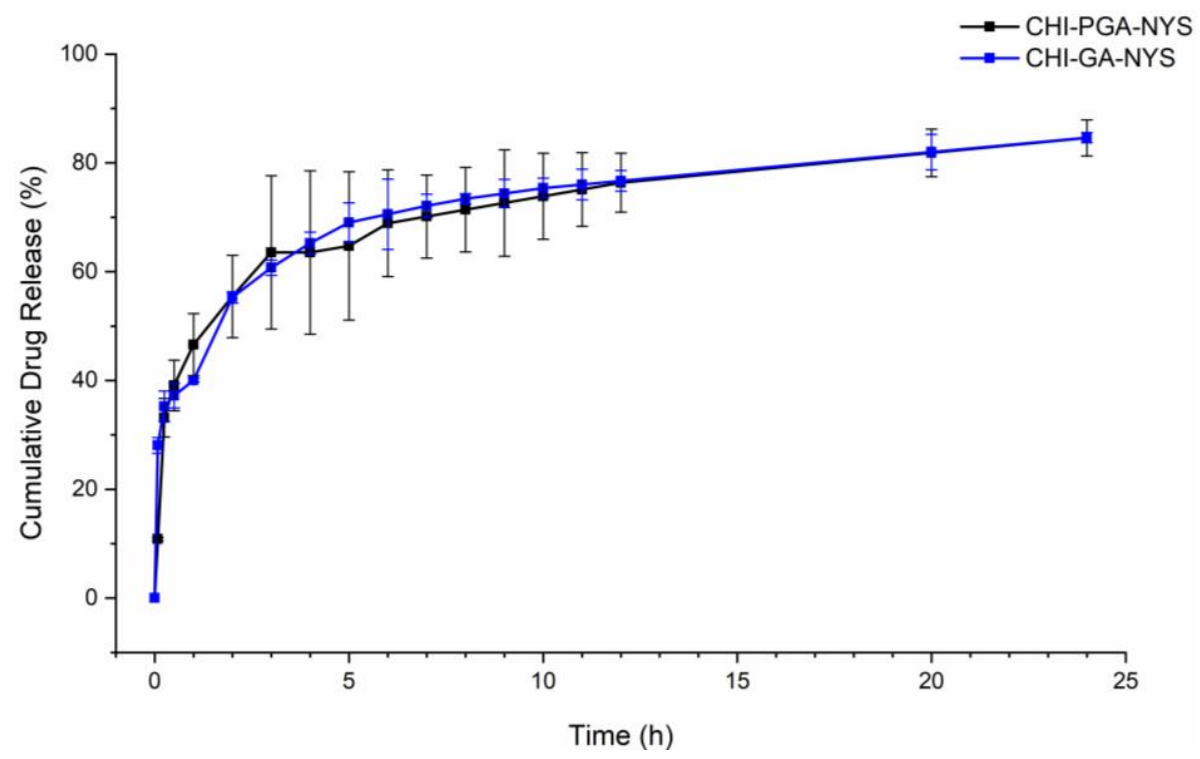

Figure 6. In vitro release profiles of CHI-GA-NYA and CHI-PGA-NYS.

Table 2. Squared correlation coefficient $\left(\mathrm{R}^{2}\right)$ and coefficients obtained after regression of the release data utilizing Higuchi and Korsmeyer-Peppas mathematical models.

\begin{tabular}{l|l|c|c} 
Model & \multicolumn{1}{|c|}{ CHI-GA } & CHI-PGA \\
\hline \multirow{2}{*}{ Higuchi } & $\mathrm{K}$ & 0.2354 & 0.2325 \\
\cline { 2 - 4 } & Adjusted R & 0.4291 & 0.5143 \\
\cline { 2 - 4 } & \multirow{2}{*}{ RSS } & 0.5016 & 0.4671 \\
& & & \\
\hline \multirow{2}{*}{ Korsemeyer-Peppas } & $\mathrm{K}$ & 0.4713 & 0.4491 \\
\cline { 2 - 4 } & $\mathrm{n}$ & 0.1998 & 0.2166 \\
\cline { 2 - 4 } & Adjusted R & 0.9815 & 0.9608 \\
\cline { 2 - 4 } & RSS & 0.0152 & 0.0354
\end{tabular}

Data obtained from the drug release profiles were fitted to the Higuchi model $(F=$ $\left.K_{H} t^{\frac{1}{2}}\right)$ and Korsmeyer-Peppas model $\left(F=k_{K-P} t^{n}\right)$ and compared with some kinetic model parameters such as release rate constant $(\mathrm{k})$, coefficient of determination $\left(\mathrm{R}^{2}\right)$, release exponent 
(n), residual sum of square (RSS) (Table 2). The higher $\mathrm{R}^{2}$ and the smaller RSS indicated a better fit of release data into the model.

The Higuchi model describes a direct proportionality between the cumulative fraction of the drug released vs. time in a pseudo-stationary state. Therefore the release of the drug is defined as the mass transfer from the release system to the medium [47]; the Korsmeyer-Peppas model, on the other hand, is based on Fick's law and is useful when the release mechanism is controlled by the relaxation of polymer chains [48]. According to this model, the value of $n$ identifies the specific release mechanism. Values below 0.5 may be due to the diffusion of drugs partially through a swollen matrix and hydrated pores, as observed in this formulation. This model is often applied for drug release profile analysis in polymeric systems.

The Korsmeyer-Peppas model was the best fit for CHI-GA and CHI-PGA films, with $\mathrm{R}^{2}$ of 0.98 and 0.96 and RSS of 0.0152 and 0.0354 , respectively. Fitting indicates that NYS release depends on polyelectrolytes' hydrophilicity and is not controlled solely by the drug's diffusion into the medium.

\subsection{In vitro determination of antifungal activity.}

The in vitro antifungal activity of the formulated films was observed over a period of $72 \mathrm{~h}$ (Table 3). Placebo CHI-PGA films showed no inhibition zones against any of the strains studied. However, an inhibitory effect was observed in the CHI-GA films. The antimicrobial activity of GA and CHI has been described previously by other authors [49,50]. Although only for $\mathrm{CHI}$, a mechanism has been proposed: the electrostatic interaction between positively charged $\mathrm{R}_{-} \mathrm{NH}_{3}{ }^{+}$sites on $\mathrm{CHI}$ and negatively charged microbial cell membranes is responsible for cellular lysis. It is assumed to be the primary antimicrobial mechanism [51,52].

Table 3. Antifungal activity of films. Inhibition zone diameters (mm) at $72 \mathrm{~h}$.

\begin{tabular}{l|c|c|c|c} 
& CHI-PGA & CHI-GA & CHI-PGA-NYS & CHI-GA-NYS \\
\hline C. albicans ATCC 14053 & - & $10 \pm 1.0$ & $35 \pm 2.5$ & $38 \pm 2.0$ \\
\hline C. albicans ATCC 90028 & - & $9 \pm 1.5$ & $38 \pm 1.0$ & $41 \pm 2.0$ \\
\hline Pichia kudriavzevii (C. krusei) WT & - & $9 \pm 1.0$ & $18 \pm 2.0$ & $16 \pm 0.5$
\end{tabular}

Table 4. ANOVA comparisons of antifungal activity of films.

\begin{tabular}{c|c|c} 
& F & P \\
\hline C. albicans ATCC 14053 & 189.1 & $<0.0001$ \\
\hline CHI-GA vs. CHI-PGA-NYS & & $<0.0001$ \\
\hline CHI-GA vs. CHI-GA-NYS & & $<0.0001$ \\
\hline CHI-PGA-NYS vs. CHI-GA-NYS & & $<.2195$ \\
\hline C. albicans ATCC 90028 & 387.7 & $<0.0001$ \\
\hline CHI-GA vs. CHI-PGA-NYS & & $<0.0001$ \\
\hline CHI-GA vs. CHI-GA-NYS & & 0.1215 \\
\hline CHI-PGA-NYS vs. CHI-GA-NYS & & 0.0004 \\
\hline Pichia kudriavzevii C. krusei) WT & 38.29 & 0.0004 \\
\hline CHI-GA vs. CHI-PGA-NYS & & 0.0016 \\
\hline CHI-GA vs. CHI-GA-NYS & & 0.2324
\end{tabular}

Both drug-loaded formulations presented inhibition zones for the three Candida strains with no statistically significant difference between the films despite finding an inhibitory effect on the placebo CHI-GA film (Table 4). This can be explained since the inhibition of the placebo films was found only when the formulation had direct contact with the culture media while NYS diffused through the plate. This result correlates with the finding of similar drug release profiles. 


\subsection{Adhesion properties of films.}

Mucoadhesive properties of the films were tested against rabbit's intestinal mucosa. This model has been previously used to assess the capacity of mucoadhesion of drug delivery formulations due to its simplicity and availability [31,53]. Besides, the results from the mucoadhesive evaluations correlate with the bucoadhesive properties of the tested materials, as previously reported [54,55].

The films showed mucoadhesive capacity in the tested model, and no interaction was found between the films and the negative control (filter paper). No significant differences were found for $\mathrm{F}_{\max }$ and $\mathrm{W}_{\mathrm{ad}}$ among the films (loaded and unloaded). When tested against HPMC tablets (a well-known mucoadhesive), a similar Fmax was found between the films and the tablets; nonetheless, a significantly higher $\mathrm{W}_{\text {ad }}$ was found for the CHI-GA and CHI-GA-NYS films (Table 5, Figure 7). Therefore, even though similar forces were required to detach the films and the tablets, the films remained attached longer.

Table 5. Mucoadhesiveness tests for placebo and NYS loaded films.

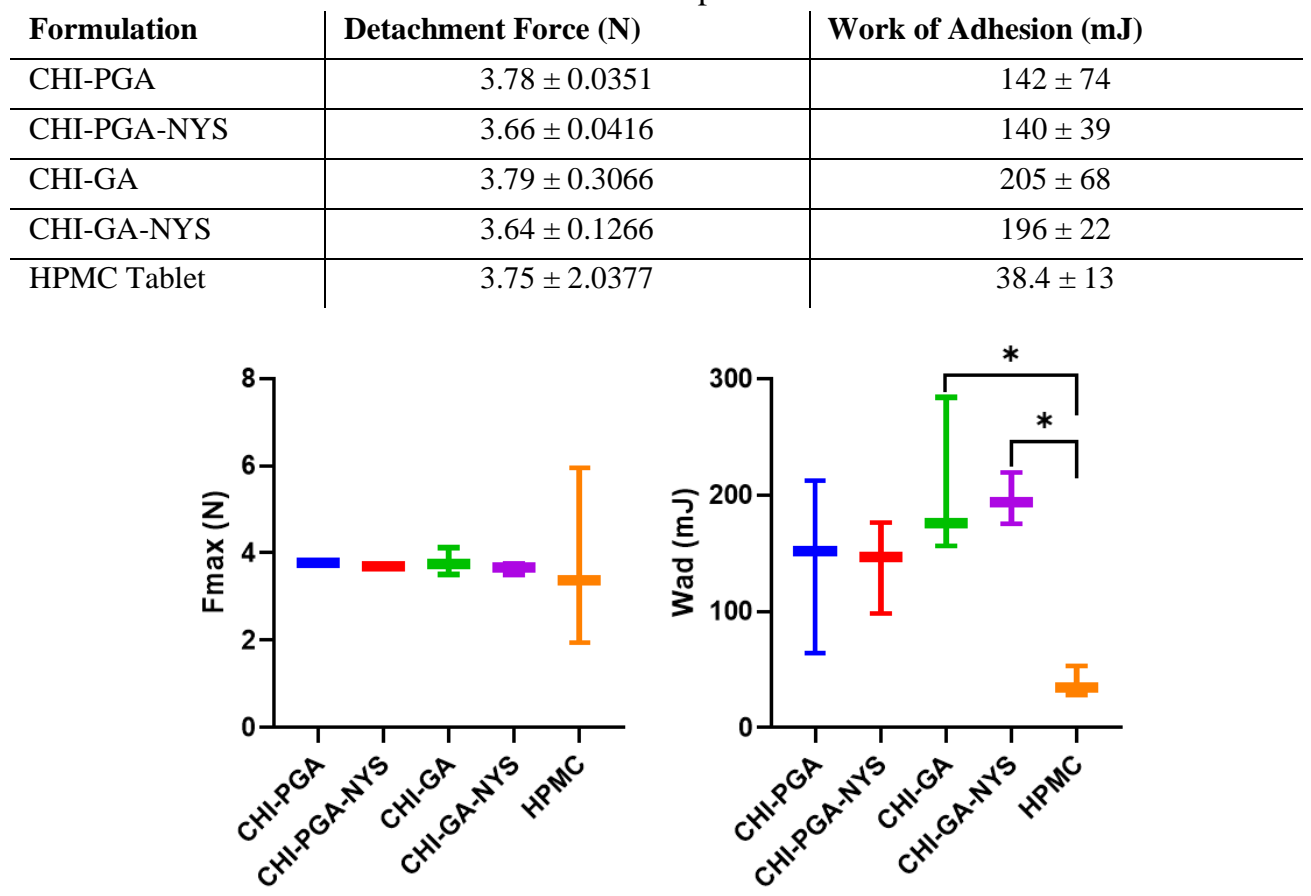

Figure 7. Detachment force $\left(\mathrm{F}_{\max }\right)$ and work of adhesion $\left(\mathrm{W}_{\mathrm{ad}}\right)$ of the films, compared with HPMC tablets.

$*$ indicate $\mathrm{p}<0.5$

The films' mucoadhesive properties may be related to the positive charge of CHI from amino groups, which can interact with the negative charges of sialic acid and mucin sulfate residues [56]. Also, the film's water uptake allows polymers to have greater chains' mobility that facilitates interdiffusion into the mucous layer; this phenomenon is known to be one of the mechanisms responsible for mucoadhesion [57]. Generally, a higher water uptake degree relates to better adhesion as this leads to rapid expulsion of water by mucous tissue and the opening of polymer chains for interpenetration [58]. The amount of the drug present in the films did not lower the mucoadhesive capacity significantly.

\section{Conclusions}

In this work, two film-shaped systems for NYS release were developed and characterized with mucoadhesion characteristics and sustained release. The systems are based 
on polyelectrolyte complexes between chitosan and anionic biopolymers, gum arabic, and polygalacturonic acid. The formation of the polyelectrolyte complex was demonstrated using FT-IR and DSC-TGA. The films obtained showed sustained release kinetics explained by the Korsmeyer-Peppas model, with a rapid initial drug release followed by a slower release that could be beneficial in oral application, as it is similar to administering a loading dose that quickly reaches therapeutic concentrations of the drug and then is maintained by sustained release. The formulations loaded with NYS showed antimicrobial activity in the three Candida strains tested; a minor effect was seen in the placebo formulation of chitosan and gum arabic, but no antimicrobial effect was found in the placebo containing polygalacturonic acid. The formulation showed a similar mucoadhesion capacity in terms of $F_{\max }$ compared to HPMC tablets and a higher $\mathrm{W}_{\mathrm{ad}}$ that was not modified by the addition of NYS. Future work with various antimicrobial drugs could widen the possible applications of these release systems.

\title{
Funding
}

Project supported by the 20th Internal Call for Research Projects UABC and the Program for Strengthening Academic Bodies SEP/PRODES 2018.

\section{Acknowledgments}

\begin{abstract}
The authors are thankful for the Consejo Nacional de Ciencia y Tecnología (CONACYT) for the fellowship provided to a graduate student to realize this work, CVU No. 686850.
\end{abstract}

\section{Conflicts of Interest}

The authors declare no conflict of interest.

\section{References}

1. Wittebole, X.; De Roock, S.; Opal, S.M. A Historical Overview of Bacteriophage Therapy as an Alternative to Antibiotics for the Treatment of Bacterial Pathogens. Virulence 2013, 5, 226-235, https://doi.org/10.4161/viru.25991.

2. Carmello, J.C.; Alves, F.; G. Basso, F.; de Souza Costa, C.A.; Bagnato, V.S.; Mima, E.G. de O.; Pavarina, A.C. Treatment of Oral Candidiasis Using Photodithazine ${ }^{\circledR}$ - Mediated Photodynamic Therapy In Vivo. PLoS One 2016, 11, e0156947, https://doi.org/10.1371/journal.pone.0156947.

3. Hellstein, J.W.; Marek, C.L. Candidiasis: Red and White Manifestations in the Oral Cavity. Head Neck Pathol. 2019, 13, 25-32, https://doi.org/10.1007/s12105-019-01004-6.

4. Millsop, J.W.; Fazel, N. Oral Candidiasis. Clin. Dermatol. 2016, 34, 487-494, https://doi.org/10.1016/j.clindermatol.2016.02.022.

5. Bedair, A.A.; Darwazeh, A.M.G.; Al-Aboosi, M.M. Oral Candida Colonization and Candidiasis in Patients with Psoriasis. Oral Surg. Oral Med. Oral Pathol. Oral Radiol. 2012, 114, 610-615, https://doi.org/10.1016/J.OOOO.2012.05.011.

6. Shekatkar, M.; Kheur, S.; Gupta, A.A.; Arora, A.; Raj, A.T.; Patil, S.; Khan, S.S.; Desai, A.; Carroll, W.B.; Awan, K.H. Oral Candidiasis in Human Immunodeficiency Virus-Infected Patients under Highly Active Antiretroviral Therapy. Disease-a-Month 2021, 101169.

7. d'Enfert, C.; Kaune, A.-K.; Alaban, L.-R.; Chakraborty, S.; Cole, N.; Delavy, M.; Kosmala, D.; Marsaux, B.; Fróis-Martins, R.; Morelli, M.; et al. The Impact of the Fungus-Host-Microbiota Interplay upon Candida Albicans Infections: Current Knowledge and New Perspectives. FEMS Microbiol. Rev. 2021, 45, 1-55, https://doi.org/10.1093/femsre/fuaa060.

8. De Araújo, J.F.; De Oliveira, A.E.F.; De Carvalho, H.L.C.C.; Roma, F.R.V.D.O.; Lopes, F.F. Principais Manifestações Bucais Em Pacientes Pediátricos HIV Positivos e o Efeito Da Terapia Antirretroviral Altamente Ativa. Cienc. e Saude Coletiva 2018, 23, 115-122, https://doi.org/10.1590/141381232018231.19072015.

9. Goulart, L.S.; Souza, W.W.R. de; Vieira, C.A.; Lima, J.S. de; Olinda, R.A. de; Araújo, C. de Oral Colonization by Candida Species in HIV-Positive Patients: Association and Antifungal Susceptibility Study. 
Einstein (Sao Paulo) 2018, 16, eAO4224-eAO4224, https://doi.org/10.1590/S1679-45082018AO4224.

10. Vazquez, J.A. Optimal Management of Oropharyngeal and Esophageal Candidiasis in Patients Living with HIV Infection. HIV/AIDS - Res. Palliat. Care 2010, 89-101, https://doi.org/10.2147/HIV.S6660.

11. Zeng, B.-S.; Zeng, B.-Y.; Hung, C.-M.; Chen, T.-Y.; Wu, Y.-C.; Tu, Y.-K.; Lin, P.-Y.; Su, K.-P.; Stubbs, B.; Sun, C.-K.; et al. Efficacy and Acceptability of Different Antifungal Interventions in Oropharyngeal or Esophageal Candidiasis in HIV Co-Infected Adults: A Pilot Network Meta-Analysis. Expert Rev. Anti. Infect. Ther. 2021, 1-11, https://doi.org/10.1080/14787210.2021.1922078.

12. Castillo-Martínez, N.A.; Mouriño-Pérez, R.R.; Cornejo-Bravo, J.M.; Gaitán-Cepeda, L.A. Factores Relacionados a Candidiasis Oral En Niños y Adolescentes Con VIH, Caracterización de Especies y Susceptibilidad Antifúngica. Rev. Chil. infectología 2018, 35, 377-385, https://doi.org/10.4067/s071610182018000400377.

13. Pérez-Sayáns, M.; Beiro-Fuentes, R.; Otero-Rey, E.M.; Chamorro-Petronacci, C.M.; Gándara-Vila, P.; Somoza-Martín, J.M.; García-García, A.; Blanco-Carrión, A. Efficacy of Different Formulations of Nystatin in an Experimental Model of Oral Candidiasis in Sialoadenectomized Rats. J. Dent. Sci. 2021, 16, 123-130, https://doi.org/10.1016/j.jds.2020.05.031.

14. Flattery, A.M.; Abruzzo, G.K.; Gill, C.J.; Smith, J.G.; Bartizal, K. New Model of Oropharyngeal and Gastrointestinal Colonization by Candida Albicans in CD4+ T-Cell-Deficient Mice for Evaluation of Antifungal Agents. Antimicrob. Agents Chemother 1996, 40, 1604 LP - 1609, https://doi.org/10.1128/AAC.40.7.1604.

15. Jordão, C.C.; Klein, M.I.; Carmello, J.C.; Dias, L.M.; Pavarina, A.C. Consecutive Treatments with Photodynamic Therapy and Nystatin Altered the Expression of Virulence and Ergosterol Biosynthesis Genes of a Fluconazole-Resistant Candida Albicans in Vivo. Photodiagnosis Photodyn. Ther. 2021, 33, 102155, https://doi.org/10.1016/j.pdpdt.2020.102155.

16. Reis, C.P.; Roque, L.V.; Baptista, M.; Rijo, P. Innovative Formulation of Nystatin Particulate Systems in Toothpaste for Candidiasis Treatment. Pharm. Dev. Technol. 2016, 21, 282-287, https://doi.org/10.3109/10837450.2014.999783.

17. Pappas, P.G.; Kauffman, C.A.; Andes, D.R.; Clancy, C.J.; Marr, K.A.; Ostrosky-Zeichner, L.; Reboli, A.C.; Schuster, M.G.; Vazquez, J.A.; Walsh, T.J.; et al. Clinical Practice Guideline for the Management of Candidiasis: 2016 Update by the Infectious Diseases Society of America. Clin. Infect. Dis. 2015, 62, e1-e50.

18. Scheibler, E.; Garcia, M.C.R.; Medina da Silva, R.; Figueiredo, M.A.; Salum, F.G.; Cherubini, K. Use of Nystatin and Chlorhexidine in Oral Medicine: Properties, Indications and Pitfalls with Focus on Geriatric Patients. Gerodontology 2017, 34, 291-298, https://doi.org/10.1111/ger.12278.

19. Lyu, X.; Zhao, C.; Yan, Z.M.; Hua, H. Efficacy of Nystatin for the Treatment of Oral Candidiasis: A Systematic Review and Meta-Analysis. Drug Des. Devel. Ther. 2016, 10, 1161-1171, https://doi.org/10.2147/DDDT.S100795.

20. Gómez-Guillén, M.C.; Montero, M.P. Enhancement of Oral Bioavailability of Natural Compounds and Probiotics by Mucoadhesive Tailored Biopolymer-Based Nanoparticles: A Review. Food Hydrocoll 2021, 118, https://doi.org/10.1016/j.foodhyd.2021.106772.

21. George, A.; Shah, P.A.; Shrivastav, P.S. Natural Biodegradable Polymers Based Nano-Formulations for Drug Delivery: A Review. Int. J. Pharm. 2019, 561, 244-264, https://doi.org/10.1016/J.IJPHARM.2019.03.011.

22. Tong, X.; Pan, W.; Su, T.; Zhang, M.; Dong, W.; Qi, X. Recent Advances in Natural Polymer-Based Drug Delivery Systems. React. Funct. Polym. 2020, 148, 104501.

23. Potaś, J.; Szymańska, E.; Winnicka, K. Challenges in Developing of Chitosan - Based Polyelectrolyte Complexes as a Platform for Mucosal and Skin Drug Delivery. Eur. Polym. J. 2020, 140, 110020.

24. Shah, S.; Leon, L. Structural Dynamics, Phase Behavior, and Applications of Polyelectrolyte Complex Micelles. Curr. Opin. Colloid Interface Sci. 2021, 53, 101424.

25. Wu, D.; Zhu, L.; Li, Y.; Zhang, X.; Xu, S.; Yang, G.; Delair, T. Chitosan-Based Colloidal Polyelectrolyte Complexes for Drug Delivery: A Review. Carbohydr. Polym. 2020, 238, 116126.

26. Barbosa, S.; Agostini, N.; Henrique, I.; Figueiredo, R.; Sousa, E. De; Silva, R.; Tavares, J.; Freitas, J.; Silvestre, L.; Reis, T.; et al. Preclinical Evaluation of Methotrexate-Loaded Polyelectrolyte Complexes and Thermosensitive Hydrogels as Treatment for Rheumatoid Arthritis. Eur. J. Pharm. Sci. 2021, 163, https://doi.org/10.1016/j.ejps.2021.105856.

27. Solomevich, S.O.; Dmitruk, E.I.; Bychkovsky, P.M.; Salamevich, D.A.; Kuchuk, S. V; Yurkshtovich, T.L. Biodegradable Polyelectrolyte Complexes of Chitosan and Partially Crosslinked Dextran Phosphate with Potential for Biomedical Applications. Int. J. Biol. Macromol. 2021, 169, 500-512, https://doi.org/10.1016/j.ijbiomac.2020.12.200.

28. Kilicarslan, M.; Ilhan, M.; Inal, O.; Orhan, K. Preparation and Evaluation of Clindamycin Phosphate Loaded Chitosan/Alginate Polyelectrolyte Complex Film as Mucoadhesive Drug Delivery System for Periodontal Therapy. Eur. J. Pharm. Sci. 2018, 123, 441-451, https://doi.org/10.1016/j.ejps.2018.08.007.

29. Zhang, X.; Liu, D.; Jin, T.Z.; Chen, W.; He, Q.; Zou, Z.; Zhao, H.; Ye, X.; Guo, M. Preparation and Characterization of Gellan Gum-Chitosan Polyelectrolyte Complex Films with the Incorporation of Thyme Essential Oil Nanoemulsion. Food Hydrocoll. 2021, 114, 106570, https://doi.org/10.1016/j.foodhyd.2020.106570. 
30. Sims, C.R.; Paetznick, V.L.; Rodriguez, J.R.; Chen, E.; Ostrosky-Zeichner, L. Correlation between Microdilution, E-Test, and Disk Diffusion Methods for Antifungal Susceptibility Testing of Posaconazole against \&lt;Em\&gt;Candida\&lt;/Em\&gt; Spp. J. Clin. Microbiol. 2006, 44, 2105-2108, https://doi.org/10.1128/JCM.02591-05.

31. Maria, S.; Sarwar, H.S.; Sohail, M.F.; Imran, M.; Salman Qureshi, O.; Raza, A.; Ahmad, N.M.; Iqbal, A.; Shahnaz, G. Synthesis and Characterization of Pre-Activated Thiolated Chitosan Nanoparticles for Oral Delivery of Octreotide. J. Drug Deliv. Sci. Technol. 2020, 58, 101807, https://doi.org/10.1016/j.jddst.2020.101807.

32. Roque, L.; Alopaeus, J.; Reis, C.; Rijo, P.; Molpeceres, J.; Hagesaether, E.; Tho, I.; Reis, C. Mucoadhesive Assessment of Different Antifungal Nanoformulations. Bioinspir. Biomim. 2018, 13, 055001, https://doi.org/10.1088/1748-3190/aad488.

33. Tejada, G.; Barrera, M.G.; Piccirilli, G.N.; Sortino, M.; Frattini, A.; Salomón, C.J.; Lamas, M.C.; Leonardi, D. Development and Evaluation of Buccal Films Based on Chitosan for the Potential Treatment of Oral Candidiasis. AAPS PharmSciTech 2017, 18, 936-946, https://doi.org/10.1208/s12249-017-0720-6.

34. Abruzzo, A.; Bigucci, F.; Cerchiara, T.; Saladini, B.; Gallucci, M.C.; Cruciani, F.; Vitali, B.; Luppi, B. Chitosan/Alginate Complexes for Vaginal Delivery of Chlorhexidine Digluconate. Carbohydr. Polym. 2013, 91, 651-658, https://doi.org/10.1016/j.carbpol.2012.08.074.

35. Castro-Ruiz, J.M. Diseño de Un Sistema Bioadhesivo de Clorhexidina Empleando Pullulan Como Matriz Para Uso En Mucosa Oral. Rev. Colomb. Cienc. Quím. Farm. 2014, 45, 35-36, https://doi.org/10.15446/rcciquifa.v45n1.58016.

36. Kaur, A.; Kaur, G. Mucoadhesive Buccal Patches Based on Interpolymer Complexes of Chitosan-Pectin for Delivery of Carvedilol. Saudi Pharm. J. 2012, 20, 21-27, https://doi.org/10.1016/j.jsps.2011.04.005.

37. Kassem, A.A.; Ismail, F.A.; Naggar, V.F.; Aboulmagd, E. Preparation and Evaluation of Periodontal Films Based on Polyelectrolyte Complex Formation. Pharm. Dev. Technol. 2015, 20, 297-305, https://doi.org/10.3109/10837450.2013.862262.

38. Mohammadi, G.; Namadi, E.; Mikaeili, A.; Mohammadi, P.; Adibkia, K. Preparation, Physicochemical Characterization and Anti-Fungal Evaluation of the Nystatin-Loaded Eudragit RS100/PLGA Nanoparticles. J. Drug Deliv. Sci. Technol. 2017, https://doi.org/10.1016/j.jddst.2017.02.004.

39. Yang, J.; Xiong, L.; Li, M.; Sun, Q. Chitosan-Sodium Phytate Films with a Strong Water Barrier and Antimicrobial Properties Produced via One-Step-Consecutive-Stripping and Layer-by-Layer-Casting Technologies. J. Agric. Food Chem. 2018, 66, 6104-6115, https://doi.org/10.1021/acs.jafc.8b01890.

40. Gierszewska, M.; Ostrowska-Czubenko, J.; Chrzanowska, E. PH-Responsive Chitosan/Alginate Polyelectrolyte Complex Membranes Reinforced by Tripolyphosphate. Eur. Polym. J. 2018, 101, 282-290, https://doi.org/10.1016/J.EURPOLYMJ.2018.02.031.

41. Mirtič, J.; Ilaš, J.; Kristl, J. Influence of Different Classes of Crosslinkers on Alginate Polyelectrolyte Nanoparticle Formation, Thermodynamics and Characteristics. Carbohydr. Polym. 2018, 181, 93-102, https://doi.org/10.1016/J.CARBPOL.2017.10.040.

42. Argüelles-Monal, W.; Cabrera, G.; Peniche, C.; Rinaudo, M. Conductimetric Study of the Interpolyelectrolyte Reaction between Chitosan and Polygalacturonic Acid. Polymer (Guildf). 2000, 41, 2373-2378, https://doi.org/10.1016/S0032-3861(99)00396-1.

43. Tsai, R.-Y.; Chen, P.-W.; Kuo, T.-Y.; Lin, C.-M.; Wang, D.-M.; Hsien, T.-Y.; Hsieh, H.-J. Chitosan/Pectin/Gum Arabic Polyelectrolyte Complex: Process-Dependent Appearance, Microstructure Analysis and Its Application. Carbohydr. Polym. 2014, 101, 752-759, https://doi.org/10.1016/j.carbpol.2013.10.008.

44. Leclercq, L.; Boustta, M.; Vert, M. Polymer Degradation as a Tool To Study Polyelectrolyte Complex Formation and Stability; 2012; 59-72.

45. Panomsuk, S.P.; Hatanaka, T.; Aiba, T.; Katayama, K.; Koizumi, T. A Study of the Hydrophilic Cellulose Matrix: Effect of Drugs on Swelling Properties. Chem. Pharm. Bull. (Tokyo). 1996, 44, 1039-1042, https://doi.org/10.1248/cpb.44.1039.

46. Macleod, G.S.; Collett, J.H.; Fell, J.T. The Potential Use of Mixed Films of Pectin, Chitosan and HPMC for Bimodal Drug Release. J. Control. Release 1999, 58, 303-310, https://doi.org/10.1016/S01683659(98)00168-0.

47. Paul, D.R. Elaborations on the Higuchi Model for Drug Delivery. Int. J. Pharm. 2011, 418, 13-17, https://doi.org/10.1016/j.ijpharm.2010.10.037.

48. Korsmeyer, R.W.; Gurny, R.; Doelker, E.; Buri, P.; Peppas, N.A. Mechanisms of Solute Release from Porous Hydrophilic Polymers. Int. J. Pharm. 1983, 15, 25-35, https://doi.org/10.1016/0378-5173(83)90064-9.

49. Baien, S.H.; Seele, J.; Henneck, T.; Freibrodt, C.; Szura, G.; Moubasher, H.; Nau, R.; Brogden, G.; Mörgelin, M.; Singh, M.; et al. Antimicrobial and Immunomodulatory Effect of Gum Arabic on Human and Bovine Granulocytes Against Staphylococcus Aureus and Escherichia Coli. Front. Immunol. 2020, 10, 3119.

50. Goy, R.C.; Morais, S.T.B.; Assis, O.B.G. Evaluation of the Antimicrobial Activity of Chitosan and Its Quaternized Derivative on E. Coli and S. Aureus Growth. Brazilian J. Pharmacogn. 2016, 26, 122-127, https://doi.org/10.1016/j.bjp.2015.09.010.

51. Goy, R.C.; De Britto, D.; Assis, O.B.G. A Review of the Antimicrobial Activity of Chitosan. Polimeros 2009, 
19, 241-247, https://doi.org/10.1590/S0104-14282009000300013.

52. Rabea, E.I.; Badawy, M.E.T.; Stevens, C. V.; Smagghe, G.; Steurbaut, W. Chitosan as Antimicrobial Agent: Applications and Mode of Action. Biomacromolecules 2003, 4, 1457-1465, https://doi.org/10.1021/bm034130m.

53. Nafee, N.A.; Ismail, F.A.; Boraie, N.A.; Mortada, L.M. Mucoadhesive Buccal Patches of Miconazole Nitrate: In Vitro/in Vivo Performance and Effect of Ageing. Int. J. Pharm. 2003, 264, 1-14, https://doi.org/10.1016/S0378-5173(03)00371-5.

54. Woertz, C.; Preis, M.; Breitkreutz, J.; Kleinebudde, P. Assessment of Test Methods Evaluating Mucoadhesive Polymers and Dosage Forms: An Overview. Eur. J. Pharm. Biopharm. 2013, 85, 843-853, https://doi.org/10.1016/j.ejpb.2013.06.023.

55. Carvalho, F.; Bruschi, M.; Evangelista, R.; Gremiao, M. Mucoadhesive Drug Delivery Systems. Brazilian J. Pharm. Sci. 2010, 46, 1-17, https://doi.org/10.4103/0975-7406.76478.

56. Smart, J.D. The Basics and Underlying Mechanisms of Mucoadhesion. Adv. Drug Deliv. Rev. 2005, 57, 15561568, https://doi.org/10.1016/j.addr.2005.07.001.

57. Peppas, N.A.; Sahlin, J.J. Hydrogels as Mucoadhesive and Bioadhesive Materials: A Review. Biomaterials 1996, 17, 1553-1561, https://doi.org/10.1016/0142-9612(95)00307-X.

58. Kharenko, E.A.; Larionova, N.I.; Demina, N.B. Mucoadhesive Drug Delivery Systems: Quantitative Assessment of Interaction Between Synthetic and Natural Polymer Films and Mucosa. Pharm. Chem. J. 2008, 42, 392-399, https://doi.org/10.1007/s11094-008-0132-8. 